\title{
Dynamic evolution of humic acids during anaerobic digestion: Exploring an effective auxiliary agent for heavy metal remediation
}

\author{
Xiqing Wang ${ }^{1}$, Tao Lyu ${ }^{2}$, Renjie Dong ${ }^{1}$, Hongtao Liu ${ }^{3}$, Shubiao $\mathrm{Wu}^{* 4}$ \\ ${ }^{1}$ Key Laboratory of Clean Utilization Technology for Renewable Energy, Ministry of Agriculture, \\ College of Engineering, China Agricultural University, 100083, Beijing, P. R. China \\ ${ }^{2}$ Cranfield Water Science Institute, Cranfield University, College Road, Cranfield, Bedfordshire, \\ MK43 OAL, UK \\ ${ }^{3}$ Institute of Geographic Science and Natural Resources Research, Chinese Academy of Sciences, \\ Beijing 100101, China \\ ${ }^{4}$ Department of Agroecology, Aarhus University, Blichers Allé 20, 8830 Tjele, Denmark \\ *Corresponding author. E-mail: wushubiao@gmail.com
}

\begin{abstract}
Information on the dynamic evolution of humic acid (HA) from anaerobic digestate and the potential of HA serving as an effective agent for remedying heavy metals is rather scarce. This study monitored the evolution of the structure and functional groups and metal-binding abilities of HA during chicken manure and corn stover anaerobic digestion (AD) processes. Higher increases in aromatic (41-66\%) and oxygen-containing functional groups (37-45\%) were observed in HA from the $A D$ of corn stover, resulting in higher metal-binding abilities for $\mathrm{Cu}(\mathrm{II}), \mathrm{Co}(\mathrm{II})$, and $\mathrm{Ni}(\mathrm{II})$ than those of chicken manure AD. Moreover, HA extracted from fast (before day 12 for chicken manure and day 16 for corn stover), and slow (day 40) methane production stages performed different complexation capacities for the heavy metals. These results reveal the mechanisms of HA and heavy metal interactions, and confirm the potential of HA extracted from AD process for the
\end{abstract}


remediation of heavy metals.

Keywords: Anaerobic process; binding capacity; humic substance; phytoremediation; toxic metals

\section{Introduction}

Soil heavy metal pollution has been considered one of the most influential threats to environmental quality and food security, because of the swift increase in industries in developing countries (Huang et al., 2020) and the impact on the natural ecosystem (Roseline et al., 2016; Sarwar et al., 2017). For example, in China, it is estimated that about $16.1 \%$ of agricultural land is contained by toxic metals and exceeds the National Soil Quality Standard (Wang et al., 2020). Some heavy metals are of great concern because they are not biodegradable and can accumulate in living organisms, thereby causing adverse effects on human health through the food chain (Dos Santos et al., 2020). Therefore, such a growing risk to food security and environmental quality calls for effective strategies to remediate heavy metal-polluted soils.

Phytoremediation is one of the commonly used in situ remediation techniques in which plants are grown in contaminated soil to remove heavy metals and/or render them harmless (Wu et al., 2010). This plant-based technology is widely accepted because of its operational simplicity, aesthetic preference, and economical visibility (Debiec-Andrzejewska et al., 2020). In general, phytoremediation includes phytoextraction, through which heavy metals are taken up by plants from the soil and accumulate in shoots and leaves, and phytostabilization, through which heavy metals 
are immobilized in soil by plant roots. The efficiency of phytoremediation largely depends on the rate of plant growth and biomass yield, sometimes with time scales of several decades. Thus, to accelerate the phytoremediation rate, many approaches have been proposed, including chelating agent addition and plant genetic manipulation (Lingua et al., 2014). However, metal chelates, such as ethylenediaminetetraacetic acid (EDTA) and diethylenetriaminepentaacetic acid (DTPA), are resistant to biodegradation and may leach into deep soil and groundwater after usage (Liu et al., 2018). On the other hand, developing genetically engineered hyperaccumulators requires tremendous efforts and time (Fasani et al., 2018). Moreover, phytoremediation would be only suitable for moderately polluted soil, because plant growth and survival are barely possible in contaminated sites with high heavy metal concentrations. Therefore, searching for environmentally friendly auxiliary agents that reduce the toxicity and mobility of heavy metals in the soil and stimulate plant growth would be a gainful strategy to promote the phytoremediation of heavy metal-contaminated soils.

Humic acid (HA), as a horticulture biostimulant, can enhance seed germination, root development, and plant growth (Canellas et al., 2015). Likewise, HA can improve the biochemical reactions inside plant cells and have direct nutritional value, as owing to its low molecular weight, it can be readily taken up by plants and result in higher biomass growth (Canellas et al., 2015; Steinberg et al., 2006). Furthermore, HA is deemed a biosurfactant that contains various functional groups, including phenols, carboxylic acids, and ketones, which can react with heavy metals through adsorption 
and complexation reactions (He et al., 2016). HA has recently been reported to serve as a terminal electron acceptor during microbial respiration, and function as an electron shuttle to drive the biogeochemical redox of heavy metals (Adhikari et al., 2017). Therefore, HA can react with a variety of heavy metals to reduce their bioavailability and consequent biological toxicity (Arslan et al., 2007). However, the current knowledge about HA serving as a remediation agent is largely derived from research on composting, which is an artificially enhanced organic matter aerobic humification process. Further research that explores alternative cost-effective HA resources for the effective remediation of heavy metals remains lacking.

Anaerobic digestion (AD) is an efficient treatment technology for the disposal of organic waste, and provides clean and affordable renewable energy to the society (Maynaud et al., 2017). The digestates generated in the AD process are often not only rich in macronutrients, such as $\mathrm{N}, \mathrm{K}, \mathrm{P}$, but also humic acids, which play very important roles in various ecological processes and terrestrial lives (Kizito et al., 2017; Luo et al., 2018; Muhmood et al., 2018). Compared with the composting process, although HA extracted from digestates has the advantage of low cost, we are not aware of any studies that have investigated the feasibility of using such substances for remedying heavy metals. Moreover, the feeding materials and formation environment of the AD process could affect HA characteristics and cause the product to differ from aerobic compostderived HA (Gao et al., 2019), demanding significant research.

To address this knowledge gap, the evolutionary dynamics of HA structure and 
function, along with the $A D$ process with different feeding materials (i.e., chicken manure and corn stover) were monitored by elemental analysis, UV/vis, Fourier transform infrared spectra (FTIR), and one-bond ${ }^{1} \mathrm{H}-{ }^{13} \mathrm{C}$ heteronuclear single quantum coherence (HSQC) nuclear magnetic resonance (NMR) imaging. In order to evaluate the effect of HA produced from the AD processes, on heavy metal remediation, HA was collected from different $A D$ stages, and its metal-binding ability was fundamentally characterized via the Stern-Volmer model. Furthermore, principal component analysis (PCA) and correlation analysis were conducted to reveal the metal-binding capabilities of different HAs. The main aim of this study is to shed light on the mechanisms of an ecofriendly and innovative strategy of using anaerobic digestate as an auxiliary agent for phytoremediation of heavy metals in soil.

\section{Materials and methods}

\subsection{Setup of the batch AD experiments}

In this study, batch AD from chicken manure and corn stover was incubated for 40 days in 120-mL brown glass bottles (an effective volume of approximately $80 \mathrm{~mL}$ ) with disposable aluminum caps. Chicken manure was collected from the Deqingyuan biogas plant, which is located in the suburbs of Beijing, China. Large particles, such as feathers, were separated and kept at $4{ }^{\circ} \mathrm{C}$ until use. The total solid (TS) and volatile solid (VS) contents of the chicken manure were $10.0 \%$ and $7.9 \%$, respectively. The corn stover was obtained from the University farm of China Agricultural University in Beijing, China, and had TS and VS values of $85.90 \%$ and $73.12 \%$, respectively. Likewise, the sludges from 
long-term laboratory-scale mesophilic $\left(37^{\circ} \mathrm{C}\right)$ digesters fed with chicken manure (TS of $4.98 \%$ and VS of $2.23 \%$ ) and corn stover (TS of $6.75 \%$ and VS of $3.45 \%$ ) were used as the corresponding inoculum for the AD of chicken manure and corn stover, respectively. Other detailed information on the characteristics of the chicken manure, corn stover, and inoculums is listed in Table S1. The organic matter ratio of the fed material and inoculum was 1:2 (Guo et al., 2018). After substrate addition, the mixture (substrate and inoculum) was stirred, and the bottle was flushed with nitrogen for $1 \mathrm{~min}$ and immediately covered with a cap of silica gel. The bottles were marked and placed under mesophilic conditions $\left(37 \pm 1^{\circ} \mathrm{C}\right.$ ) in a constant temperature incubator ( $\mathrm{RZH}-380 \mathrm{~A}$, artificial climate chamber, China). Each group was evaluated in triplicate. Three replicate bottles filled with inoculum alone were used as blanks in each treatment group, under the same experimental conditions.

\subsection{Characterization of methane production and organics evolution}

Daily methane production was measured using a water displacement manometer (GF-500, KIMO, France) every 1-2 d for the first 20 days, and then, every 4-5 d until day 40. Likewise, to obtain detailed information on AD performance, such as lag phase and maximum methane production rate, the Gompertz model was used to fit the $\mathrm{CH}_{4}$ production data (Zhang et al., 2014). In addition, samples of anaerobically digested sludge $(50 \mathrm{~mL})$ in the batch process were collected every $5 \mathrm{~d}$, and physicochemical properties, such as $\mathrm{pH}, \mathrm{TS}$, and VS (Table S2), were analyzed according to standard methods (Luo et al., 2018). 
The excitation-emission matrix (EEM) spectra of the digestates were recorded using a fluorescence spectrophotometer (Aqualog, HORIBA), to analyze evolution of the organic matter during the AD process. The sampled digestate was first diluted with distilled water 50 times before fluorescence spectra analysis. The emission wavelengths (250-550 nm) and excitation wavelengths $(250-600 \mathrm{~nm})$ over the range were observed in 5 and $3 \mathrm{~nm}$ increments, respectively. The Rayleigh and Raman scattering of the EEM data were calibrated using the method described by Wang et al. (2020). Finally, the parallel factor (PARAFAC) analysis was carried out using MATLAB R2018a (MathWorks, USA) with the DOMFluor Toolbox. Through the PARAFAC model analysis, the EEM spectra can be decomposed into three matrices: score, excitation (Ex) loading, and emission (Em) loading. Specific Ex/Em loading was used to identify different fluorescent components. The maximum fluorescence intensity (Fmax) (a.u.) value in the score matrix indicated the concentration of the corresponding component. The Ex/Em loadings and EEM contours of the fluorescent components are listed in Table S3 (Supporting Information).

\subsection{Extraction of HA from the sampled digested slurry}

The extraction and purification of HA from the sampled digested slurry were conducted according to the standard method recommended by the International Humic Substances Society (Helmke et al., 1996). Briefly, the sampled digested slurry was first shaken (200 rpm, $24 \mathrm{~h}$ ) with a mixed solution of $0.1 \mathrm{M} \mathrm{Na}_{4} \mathrm{P}_{2} \mathrm{O}_{7}$ and $0.1 \mathrm{M} \mathrm{NaOH}$ at a 1:10 (w:v) ratio at room temperature $\left(25 \pm 3{ }^{\circ} \mathrm{C}\right)$. The supernatant was filtered through a $0.45-\mu \mathrm{m}$ Millipore membrane after $20 \mathrm{~min}$ of centrifugation at $11,000 \mathrm{rpm}$. The 
procedure was repeated three times, and the supernatant was filtered through a 0.45 $\mu \mathrm{m}$ Millipore membrane, acidified with $6 \mathrm{M} \mathrm{HCl}$ to $\mathrm{pH} \mathrm{1}$, and left overnight. The precipitate was separated from the liquid phase by centrifugation (5000 rpm, $10 \mathrm{~min}$ ), resuspended in $100 \mathrm{~mL}$ of $\mathrm{NaOH}$ and $\mathrm{Na}_{4} \mathrm{P}_{2} \mathrm{O}_{7}$ mixed solution, and shaken overnight. The solution was then centrifuged (5000 rpm, $10 \mathrm{~min}$ ), and the liquid phase was acidified with $0.1 \mathrm{M} \mathrm{HCl} / 0.3 \mathrm{M}$ hydrogen fluoride to $\mathrm{pH} \mathrm{1,} \mathrm{left} \mathrm{to} \mathrm{stand} \mathrm{overnight,} \mathrm{and}$ recentrifuged. The precipitate was dialyzed against distilled water until $\mathrm{Cl}^{-}$could no longer be detected (Zhao et al., 2020).

\subsection{Humic acid characterization}

The carbon $(\mathrm{C})$, hydrogen $(\mathrm{H})$, and nitrogen $(\mathrm{N})$ contents of the HA were analyzed using an elemental analyzer (Vario EL cube, Germany). Likewise, the $\mathrm{H} / \mathrm{C}$ and $\mathrm{C} / \mathrm{N}$ atomic ratios of the HA were calculated based on the elemental analysis results.

The specific UV absorbances (SUVAs) at $254 \mathrm{~nm}$ and $280 \mathrm{~nm}$ were measured using a UV-vis spectrophotometer (Shimadzu, UV-2600). SUVA 254 was used to characterize the relative HA aromaticity. Similarly, SUVA 280 is suitable for tracking the $\pi-\pi^{*}$ electron transitions for phenolic substances, aniline derivatives, benzoic acids, polyenes, and polycyclic aromatic hydrocarbons. Briefly, $10 \mathrm{mg}$ of each solution was solubilized in 10 $\mathrm{mL}$ of $0.05 \mathrm{~mol} \mathrm{~L}^{-1} \mathrm{NaHCO}_{3}$, with the $\mathrm{pH}$ adjusted to 8.3 using $0.2 \mathrm{M} \mathrm{NaOH}$ (Tang et al., 2018). Next, the contents of HA aliphatic and aromatic components were monitored with one-bond ${ }^{1} \mathrm{H}-{ }^{13} \mathrm{C}$ heteronuclear single quantum coherence (HSQC) nuclear magnetic resonance (NMR) imaging using an Avance III $600 \mathrm{MHz}$ spectrometer (Bruker, 
The Woodlands, TX).

Fourier transform infrared (FTIR) spectra, as a mainstream tool for determining functional groups and analyzing the structural composition of the sampled HA, was used in this study. HAs were extracted from the anaerobic digestate of chicken manure and corn stover every five days and labeled as AD $0 d, A D 5 d, A D 10 d, A D 15 d, A D 20 d, A D$ $25 d, A D 30 d, A D 35 d$, and AD 40 d. The FTIR spectra were obtained with a Nicolet IS10 FTIR spectrophotometer in the range of 4000 to $400 \mathrm{~cm}^{-1}$. The absorbance of different wavenumbers was divided by the integrated absorbance area of the representative wavenumbers and multiplied by 100 to obtain the relative content (\%). The results revealed the relative contents of different HA functional groups (Gao et al., 2019).

\subsection{Heavy metal-binding analysis}

The common heavy metal species, $\mathrm{Cu}, \mathrm{Ni}$, and Co were selected as target elements for evaluating the metal-binding ability of HA through a titration method (Xu et al., 2019). Before titration, the HA fraction was diluted to a concentration of approximately $10 \mathrm{mg}$ $\mathrm{L}^{-1}$, and $0.1 \mathrm{M}$ metal solution was added to a series of vials that contained $50 \mathrm{~mL}$ of diluted HA solution, with the help of an automatic syringe (Ohno et al., 2008). A series of experiments was performed with initial heavy metal concentrations that ranged from 5 to $100 \mu \mathrm{M}$. The $\mathrm{pH}$ of the solution was adjusted to 6.0 using $0.1 \mathrm{M} \mathrm{HCl}$ or $\mathrm{NaOH}$ to avoid precipitation. Then, the titrated solution was thoroughly mixed and placed for 24 $\mathrm{h}$ at room temperature to ensure complexation equilibrium. All experiments were performed in triplicate to obtain statistically reliable results. Afterward, the titrated 
solutions were analyzed by spectral scanning to determine the fluorescence intensity. The results were used to simulate the Stern-Volmer model (Equation 1). After confirming the suitability of the simulation model, the fluorescence intensity difference $\left(F_{0}-F\right.$, equation 1$)$ between the original HA sample and the HA sample after heavy metal adsorption was calculated to represent the specific metal-binding capacity as follows:

$$
\frac{F_{0}}{F_{0}-F}=\frac{1}{f \cdot K_{M} \cdot C_{M}}+\frac{1}{f}
$$

where $F$ and $F_{0}$ are the intensity scores of fluorescent $H A$ with and without metal addition, $f$ represents the fraction of the initial fluorescence that corresponds to metal binding, and $K_{M}$ is the conditional stability constant, which can be obtained by plotting $F_{0} / F_{0}-F$ against $1 / C_{M}$, the $C_{M}$ is the concentration of added metal.

\subsection{Data analysis}

Principal component analysis (PCA) was conducted to determine the relationship between the dynamics of metal-binding and the characteristics of HA during the entire AD process with different materials. A cluster analysis was performed according to the eigenvalues of each component, and the results were used to group similar patterns in the PCA coordinates. The eigenvalues of all the components in the PCA are shown in Table S4. The first two components of the PCA contributed to high variance eigenvalues in both the $A D$ processes; thus, they were extracted as the principal components for further analysis. Moreover, cluster analysis was performed according to the eigenvalues of the components, and the fermentation time was used as a variable. All data were analyzed using SPSS version 22.0 and Origin 8.5. Correlation analysis among the different parameters was conducted using SPSS 22.0 software (SPSS International Chicago, USA), 
and the graphs were plotted using Origin 8.5 (Origin Lab, USA).

\section{Results and Discussion}

\subsection{Methane yield and production stages}

The cumulative methane yield from the AD of chicken manure $\left(254 \pm 7 \mathrm{~mL} \mathrm{gVS}^{-1}\right)$ was significantly higher than the yield $\left(227 \pm 6 \mathrm{~mL} \mathrm{gVS}^{-1}\right)$ obtained from the AD of corn stover (Fig. 1). This result may be attributed to the high lignin content in corn stover, which limits the most bioavailable organic source for methane generation through methanogenic bacterial-mediated reactions (Croce et al., 2016). This hypothesis was also supported by the higher degradation rate of VS (38.4\%) in the AD of chicken manure than that (34.8\%) of corn stover (Table S2).

The Gompertz model, as a classical kinetic model, has been commonly used to estimate methane production through $A D$, including the maximum methane production rate and lag phase (Andriamanohiarisoamanana et al., 2020). In this study, the Gompertz model precisely described the methane production of both $A D$ processes of chicken manure $\left(R^{2}=0.978\right)$ and corn stover $\left(R^{2}=0.989\right)$ (Fig. 1 and Table S5). The lag phase time $(\lambda=-0.2)$ of the chicken manure AD was shorter than that $(\lambda=5.1)$ of corn stover (Table S5), which indicated a faster biodegradation/ methane production rate of AD from the chicken manure feeding material (Croce et al., 2016). Another previous study divided the $A D$ process in two stages, namely, the fast and slow methane production stages, which were based on the methane production rate $(K)$ generated from the Gompertz simulation model (Li et al., 2020). In this study, the methane production rate (K) from AD 
with both feeding materials first increased and then decreased (Table S5). The maximum $K$ values for $A D$ from chicken manure $\left(14.8 \mathrm{~mL} \mathrm{gVS}^{-1} \mathrm{~d}^{-1}\right)$ and corn stover $\left(13.4 \mathrm{~mL} \mathrm{gVS}^{-1}\right.$ $\mathrm{d}^{-1}$ ) were observed on days 12 and 16 , respectively. Therefore, the turning points of the fast and slow methane production stages of the AD of chicken manure (day 12) and corn stover (day 16) were identified. The distinct methane production stages could affect the evolution of HA structures and their metal-binding abilities, as discussed below.

\subsection{Transformation of organic matter composition}

Fluorescence EEM spectroscopy and PARAFAC analyses (Fig. 2) were used to analyze the composition and evolution of organic HA precursors during the AD process. Five identical fluorescent components were characterized for both AD processes, which included chicken manure feeding materials (Fig. 2a) or corn stover (Fig. 2c). Previous studies have demonstrated that components $C 1(E x / E m=327 \mathrm{~nm} / 410 \mathrm{~nm})$ and $C 3$ ( $E x / E m=366 \mathrm{~nm} / 435 \mathrm{~nm}$ ) are humic-like compounds (Wu et al., 2019). Component C2 (Ex/Em=417 nm/470 nm) is a fulvic-like compound (He et al., 2015), and components C4 $(E x / E m=294 \mathrm{~nm} / 335 \mathrm{~nm})$ and $C 5(E x / E m=276 \mathrm{~nm} / 315 \mathrm{~nm})$ are protein-like substances, namely, tyrosine-like and tryptophan-like substances (Xiao et al., 2019).

The formation of these five components differed between the two feeding materials throughout the AD processes (Fig. $2 b$ and d). In chicken manure, the relative abundances of C1 and C3 increased steadily, from $20 \%$ and $18 \%$ to $42 \%$ and $30 \%$, respectively (Fig. 2b). The relative abundances of C4 and C5 decreased from $20 \%$ and $25 \%$ to $9 \%$ and $10 \%$, respectively. Likewise, the relative abundance of C2 decreased from $19 \%$ 
to $6 \%$. The increased abundance of humic-like components ( $\mathrm{C} 1$ and $\mathrm{C} 3$ ), and the decreased abundance of protein-like (C4 and C5) and fulvic-like acid (C2) components are consistent with previously reported humification processes (Ma et al., 2019; Tang et al., 2018). Compared with chicken manure, a higher relative abundance of humic-like components (61-89\%) and a lower relative content of protein-like components (1-20\%) were observed in the corn stover AD process (Fig. $2 \mathrm{~d}$ ). This might be due to the high abundance of lignocellulosic compounds in the corn stover that can provide sufficient precursors for the synthesis of humic-like substances (Gao et al., 2019). Corn stover has a higher $\mathrm{C} / \mathrm{N}$ ratio and lignification degree; however, chicken manure is characterized by a higher level of protein and grease (Kumar et al., 2010; Zhou et al., 2014). These differences in feeding materials could also result in a relatively higher content of proteinlike components in the digestates from the chicken manure AD process.

\subsection{HA aromatization evolution}

$H A$ is generated through the humification of organics during $A D$, and the elemental compositions of HA reflect its basic nature and structure (He et al., 2012). Due to their complex structures, the $\mathrm{H} / \mathrm{C}$ and $\mathrm{C} / \mathrm{N}$ atomic ratios were calculated to obtain more detailed information on the aromatic evolution of HA (Table 1 and Table S6). The HA H/C ratio decreased during the chicken manure $A D$ process, and this indicates an increase in aromatic groups and a decrease in aliphatic HA functional groups (He et al., 2012). Meanwhile, the $\mathrm{HA} \mathrm{H} / \mathrm{C}$ ratio of the $\mathrm{AD}$ chicken manure (2.18-1.82) was higher than that (1.78-1.42) of corn stover, which indicated that the HA formed during the AD of chicken 
manure had a relatively higher content of aliphatic components (Gao et al., 2019). Moreover, the $\mathrm{C} / \mathrm{N}$ ratio decreased from 6.34 to 3.99 during the fast methane production stage for both systems, and this was attributed to the lower mineralization rate of $\mathrm{N}$ than of $C$ during the $A D$ process (Guo et al., 2019). An increasing $C / N$ trend was observed in the slow methane production stage during the $A D$ of chicken manure, and this demonstrates a stronger repolymerization effect of HA on C-rich compounds, such as aromatic substances (Zhang et al., 2019). No obvious change in $\mathrm{C} / \mathrm{N}$ ratio was observed in the corn stover $A D$ process during the slow methane generation stage, and this may be due to the abundant complex lignocellulosic compounds of the corn stover that limit the formation of aromatic substances to a certain extent (Gao et al., 2019).

Increasing trends in $\mathrm{SUVA}_{254}$ and SUVA 280 were observed during the chicken manure AD process (Table 1 ). In contrast, the SUVA 254 and SUVA 280 values initially increased and then decreased during the corn stover AD process. The increasing trend indicated an improved degree of aromaticity of the HA, which was consistent with the elemental composition results (He et al., 2014). The relative aromaticity enhancement can be ascribed to the exposure of inner aromatics during the intensive consumption of superficial labile aliphatics as the microorganism energy source (Tang et al., 2018). However, the exposed HA aromatic structures derived from corn stover can further biodegrade in the absence of a sufficient $\mathrm{C}$ source, because the original aromatics were insufficient (Tang et al., 2018). This could be the reason for the decrease in the degree of aromaticity that occurred during the slow methane production stage of the corn 
stover AD process (Amir et al., 2006; Maia et al., 2008).

The quantities of HA aromaticity and aliphaticity during different AD processes were further determined with HSQC spectroscopy. As shown in Fig. S1, the aromaticity of $\mathrm{HA}$ derived from chicken manure and corn stover increased from $28.3 \%$ and $41.2 \%$ to $45.3 \%$ and $66.7 \%$, respectively, while the aliphaticity decreased from $64.2 \%$ and $39.7 \%$ to $23.5 \%$ and $20.1 \%$, respectively, and these trends agreed with the changes in SUVA 254 and SUVA 280 (Table 1). Moreover, HA derived from corn stover showed higher aromaticity (41.2-66.7\%) and lower aliphaticity (39.7-20.1\%) than those (28.3-45.3\% for aromaticity and $64.2-23.5 \%$ for aliphaticity) of chicken manure, and this finding was consistent with the elemental composition analysis result. Therefore, we can conclude that the HA macromolecules were formed by the degradation of aliphatic and labile aromatic groups of the original $\mathrm{HA}$ and from aromatic structure reconstruction during the $A D$ processes (Yu et al., 2019).

\subsection{Variations in the HA functional groups}

The functional groups of HA derived from the AD of chicken manure and corn stover mainly varied in the FTIR spectrum range of $1000-1800 \mathrm{~cm}^{-1}$ (Fig. 3a and b). Thus, the peaks at these wavelengths were obtained for semi-quantitative analysis (Fig. S2). The broad absorption band at $1030-1230 \mathrm{~cm}^{-1}$ could be attributed to the $\mathrm{C}-\mathrm{O}$ stretching of the $-\mathrm{COOH}$ groups and $\mathrm{C}-\mathrm{H}$ bending (Zhang et al., 2019). The peak located at 1650$1720 \mathrm{~cm}^{-1}$ may be due to the stretching vibration of aromatic functional groups, such as the $\mathrm{C}=\mathrm{O}$ bonds of $-\mathrm{COOH}$ and ketones (Liu et al., 2015). The peak observed in the range 
of $1400-1650 \mathrm{~cm}^{-1}$ is due to the stretching vibrations of $-\mathrm{NH}$ groups in amides (Rodríguez et al., 2016).

When looking at the dynamic changes in relevant peak proportions (Fig. 3c, e, and g), the content of $1030-1230 \mathrm{~cm}^{-1}$ increased approximately from $37.1 \%$ to $47.2 \%$, while the area of $1400-1650 \mathrm{~cm}^{-1}$ decreased from $39.1 \%$ to $31.1 \%$, during the chicken manure AD process. In contrast, the $1650-1720 \mathrm{~cm}^{-1}$ content fluctuated in the range of $22.2-$ 23.9\%. In the corn stover AD process (Fig. $3 \mathrm{~d}, \mathrm{f}$, and h), the $1030-1230 \mathrm{~cm}^{-1}$ and 1650 $1720 \mathrm{~cm}^{-1}$ contents increased from $37.2 \%$ and $28.8 \%$ to $44.6 \%$ and $32.8 \%$, respectively, while the $1400-1650 \mathrm{~cm}^{-1}$ content decreased from $33.8 \%$ to $23.9 \%$ during the fast methane production stage (before day 16). However, no significant change was observed in the slow methane production stage (after day 16). These results indicate that the HA amides may first be degraded to serve as a carbon resource for microorganisms to produce $\mathrm{CH}_{4}$ and small molecules (Gao et al., 2019). Then, small molecules become attached to the HA units via the polymerization process and finally form complex and humified structures with a higher content of oxygen-containing functional groups (Tang et al., 2018). Moreover, HA derived from corn stover contained a higher content of aromatic functional groups (28.8-32.8\%) and a lower content of amide groups (33.8$23.8 \%)$ than that of chicken manure (22.2-23.9\% and $39.1-31.1 \%$, respectively), and this was consistent with the results of the elemental composition and HSQC spectroscopy analyses (Fig. S1).

\subsection{The capabilities and mechanisms of HA for heavy metal remediation}


The HAs, collected from different stages, that is, initial (day 0), fast (day 10 for chicken manure and day 15 for corn stover), and slow (day 40) methane production stages, of $A D$ processes with different feeding materials, were tested for their metalbinding capacities towards target heavy metals $(\mathrm{Cu}, \mathrm{Ni}$, and $\mathrm{Co})$. The fluorescence intensity dynamics that occur due to different heavy metal concentrates can be precisely described by the Stern-Volmer model $\left(R^{2}>0.98\right.$, Fig. 4). The results indicate that the differences in fluorescence intensities between the original HA (without heavy metal addition) and the samples after certain heavy metal addition can be used to represent the binding/adsorption capacity of HA with heavy metals (Wang et al., 2020; Xu et al., 2019). Thus, in Fig. 4, the higher decline in intensities suggested greater binding between HA and heavy metals.

The HA collected from different fermentation periods showed clear differences in metal-binding abilities, especially for $\mathrm{Cu}$ and $\mathrm{Ni}$ (Fig. 4). Specifically, the HA collected on day 40 of the chicken manure $A D$ process showed higher binding capacities (greater intensity declines) compared with the HA collected on days 10 and 0 (Fig. $4 \mathrm{a}$ and c). The same trend was also observed in the corn stover AD process (Fig. $4 \mathrm{~d}-\mathrm{f}$ ). These findings were supported by previous studies that showed how anaerobic digestates that form at the end of the $A D$ process present higher heavy metal adsorption compared with digestates from the early stage (Xu et al., 2019).

Lee et al. (2020) reported that the abundance of aromatic structures could be attributed to the complexation reactions of heavy metals by HA (Lee et al., 2020). In this 
study, a PCA was performed to explore the mechanisms of HA structure evolution (Fig. 5). In particular, the samples from the fast methane production stage for both $A D$ processes were grouped and located in the left area of the coordinate, which was positively related to aliphaticity and negatively related to aromaticity. During the slow methane production stage, the samples from both $A D$ processes were grouped and moved towards the right area in the coordinates, which represents positive contributions by both humification and aromaticity PCA components. These results demonstrate that the HA collected at day 40 (end of the slow methane generation stage) contained higher aromaticity, which could lead to the highest metal-binding ability, compared with the HAs collected earlier (Fig. 4). In addition, higher HA aromaticity (41.2$66.7 \%)$ was observed in the $A D$ of corn stover than $(28.3-45.3 \%)$ in that of chicken manure (Fig. S1). This result also led to the general higher metal-binding ability of HA derived from corn stover than that derived from chicken manure (Fig. 4).

The metal-binding abilities of HA also differed with respect to the heavy metal species. In the fast methane production stage (red dots in Fig. 4), the binding capacity of HA from chicken manure followed the order $\mathrm{Co}>\mathrm{Cu}>\mathrm{Ni}$, while that from the corn stover $A D$ process was $\mathrm{Cu}>\mathrm{Co}>\mathrm{Ni}$. The different performances can be explained by the mechanisms of the steric electrostatic interaction and complexing bonds between metals and active HA functional groups (Li et al., 2019). The proportions of the different HA functional groups according to FTIR detection (Fig. 3) and the corresponding metalbinding capacities were used for a correlation analysis (Fig. 6). The clear linear 
relationship between the two factors supports the importance of HA functional groups for heavy metal adsorption (Boguta et al., 2019).

The complex strength depends on the physical properties of the metals, where the metal adsorption declines with increasing hydrated radius (Wei et al., 2017). Thus, Cu and $\mathrm{Co}$, with lower hydration radii compared with $\mathrm{Ni}$, could be absorbed by HA from both AD processes (Wei et al., 2019). Moreover, the differences in HA functional groups could also affect metal-binding. As shown in Fig. 6a, the higher content of HA amide groups $(\mathrm{N}-\mathrm{H})$ contributed to the higher binding of Co during the fast methane production stage of chicken manure, and this could be the reason for the order of highest metal-binding. However, the higher oxygen-containing group content also contributed to the higher binding of Co during the fast methane production of corn stover AD (Fig. 6d). Likewise, there was no significant correlation between the binding of $\mathrm{Cu}$ and functional groups during the fast methane production stage of chicken manure and corn stover $A D$ processes (Fig. 6 a-d), and this suggests that electrostatic interactions dominates the binding reaction with $\mathrm{Cu}$ (Wei et al., 2019).

Compared with the fast methane production stage, during the slow methane production stage (blue dots in Fig. 4), HA aliphatic and amide groups contributed to the progressive transformation of polysaccharides to other oxygen-containing groups, such as phenol and carboxylic groups, and this resulted in a decrease in the number of amide groups, as the oxygen-containing groups increased. The HA oxygen-containing groups were positively related to the binding of $\mathrm{Cu}$ for the chicken manure AD process (Fig. 6f). 
Thus, the metal binding capacity of HA from chicken manure followed the order of $\mathrm{Cu}>\mathrm{Co}>\mathrm{Ni}$, which is consistent with the results reported by Soares da Silva et al. (2020). Notably the hydrophilic structure of humic substances causes a $\mathrm{Cu}(\mathrm{II})$ binding preference for hydroxylated groups $(\mathrm{O}-\mathrm{H})$, and the higher aromaticity $(\mathrm{C}=\mathrm{C})$ privileges the interactions (Silva et al., 2020). Regarding the corn stover AD process, the oxygencontaining groups were also positively related to the binding ability of $\mathrm{Cu}$ and $\mathrm{Co}$. However, the correlation between oxygen-containing groups and Co was higher than that of $\mathrm{Cu}$, which suggests that oxygen-containing groups have a preferential affinity towards Co.

\subsection{Environmental applications and further research needs}

HA can provide dual benefits with respect to the heavy metal-contaminated soil phytoremediation, through accelerating plant growth as a biostimulant (Canellas et al., 2015) and binding/immobilizing heavy metals as a biosurfactant (Hazrati et al., 2020; He et al., 2016). While there are a few limitations, the majority of experience with HA heavy metal remediation is being extrapolated based on aerobic composting processes (Lipczynska-Kochany, 2018; Piccolo et al., 2019). The present study explored a new sustainable source of effective HA that was derived from current widely-used anaerobic digestion technologies.

The feeding materials significantly altered the HA structure evolution, and resulted in differences in heavy metal adsorption/binding. For example, the HA derived from the corn stover AD process showed superior adsorption for all three heavy metals (i.e., $\mathrm{Cu}$, 
$\mathrm{Ni}$, and $\mathrm{Co}$ ) compared with the HA generated from the chicken manure AD process (Fig. 4). The metal-binding capabilities heavily depended on HA characteristics, including aromaticity (Table 1) and functional groups (Fig. 3 and 6). Thus, the HA from the slow methane production stage showed higher metal-binding capabilities towards $\mathrm{Cu}$ and $\mathrm{Ni}$, but not Co (Fig. 4). Nonetheless, this study first confirmed that the AD process provides a cheap and environment-friendly approach for HA generation towards effective heavy metal remediation. Moreover, the results may also provide a guideline for further application, in particular, for collecting the most appropriate digestates that target specific heavy metals. Based on the knowledge gained from this fundamental research, further studies should focus on investigating the synergistic effect of HA on plant growth, as well as the influences of more complex environmental conditions, such as $\mathrm{pH}$ and temperature, on heavy metal removal in a realistic environment.

\section{Conclusions}

This study monitored the evolution of HA during AD processes and validated the great potential of HA for heavy metal remediation. The decomposition of initial components (such as aliphatic and amide substances) and re-polymerization of HA aromatic compounds were observed during the $A D$ process. Likewise, the distinct $H A$ structure evolution contributed to the different affinities for target heavy metals, $\mathrm{Cu}, \mathrm{Ni}$, and Co. The higher increases in aromatic and oxygen-containing functional group (such as $-\mathrm{COOH}$ and $-\mathrm{C}-\mathrm{O}-$ ) content were obtained in $\mathrm{HA}$ from the $\mathrm{AD}$ of corn stover, resulting in higher metal-binding abilities than those of AD of chicken manure. 


\section{Appendix A. Supplementary data}

Supplementary data to this article can be found in the Supporting Information.

\section{References}

Adhikari, D., Zhao, Q., Das, K., Mejia, J., Huang, R., Wang, X., Poulson, S.R., Tang, Y., Roden, E.E., Yang, Y., 2017. Dynamics of ferrihydrite-bound organic carbon during microbial Fe reduction. Geochim. Cosmochim. Acta 212, 233. https://doi.org/https://doi.org/10.1016/j.gca.2017.06.017

Amir, S., Hafidi, M., Lemee, L., Bailly, J.-R., Merlina, G., Kaemmerer, M., Revel, J.-C., Ambles, A., 2006. Structural characterization of fulvic acids, extracted from sewage sludge during composting, by thermochemolysis-gas chromatography-mass spectrometry. J. Anal. Appl. Pyrolysis 77, 149-158. https://doi.org/https://doi.org/10.1016/j.jaap.2006.02.004

Andriamanohiarisoamanana, F.J., Ihara, I., Yoshida, G., Umetsu, K., 2020. Kinetic study of oxytetracycline and chlortetracycline inhibition in the anaerobic digestion of dairy manure. Bioresour. Technol. 315, 123810. https://doi.org/10.1016/j.biortech.2020.123810

Arslan, G., Cetin, S., Pehlivan, E., 2007. Removal of $\mathrm{Cu}(\mathrm{II})$ and $\mathrm{Ni}(\mathrm{II})$ from aqueous solution by lignite-based humic acids. Energy Sources, Part A Recover. Util. Environ. Eff. 29, 619-630. https://doi.org/10.1080/009083190957711

Boguta, P., D’Orazio, V., Senesi, N., Sokołowska, Z., Szewczuk-Karpisz, K., 2019. Insight into the interaction mechanism of iron ions with soil humic acids. The effect of the $\mathrm{pH}$ and chemical properties of humic acids. J. Environ. Manage. 245, 367-374. https://doi.org/10.1016/j.jenvman.2019.05.098

Canellas, L.P., Olivares, F.L., Aguiar, N.O., Jones, D.L., Nebbioso, A., Mazzei, P., Piccolo, A., 2015. Humic and fulvic acids as biostimulants in horticulture. Sci. Hortic. (Amsterdam). 196, 15-27. https://doi.org/10.1016/j.scienta.2015.09.013

Croce, S., Wei, Q., D'Imporzano, G., Dong, R., Adani, F., 2016. Anaerobic digestion of straw and corn stover: The effect of biological process optimization and pre-treatment on total biomethane yield and energy performance. Biotechnol. Adv. 34, 1289-1304. https://doi.org/https://doi.org/10.1016/j.biotechadv.2016.09.004

Debiec-Andrzejewska, K., Krucon, T., Piatkowska, K., Drewniak, L., 2020. Enhancing the plants growth and arsenic uptake from soil using arsenite-oxidizing bacteria. Environ. Pollut. 264, 114692. https://doi.org/10.1016/j.envpol.2020.114692 
dos Santos, J.V., Fregolente, L.G., Moreira, A.B., Ferreira, O.P., Mounier, S., Viguier, B., Hajjoul, H., Bisinoti, M.C., 2020. Humic-like acids from hydrochars: Study of the metal complexation properties compared with humic acids from anthropogenic soils using PARAFAC and time$\begin{array}{lllll}\text { resolved } & \text { fluorescence. } & \text { Sci. } & \text { Total } & \text { Environ. }\end{array}$ https://doi.org/10.1016/j.scitotenv.2020.137815

Fasani, E., Manara, A., Martini, F., Furini, A., DalCorso, G., 2018. The potential of genetic engineering of plants for the remediation of soils contaminated with heavy metals. Plant Cell Environ. 41, 1201-1232. https://doi.org/10.1111/pce.12963

Gao, X., Tan, W., Zhao, Y., Wu, J., Sun, Q., Qi, H., Xie, X., Wei, Z., 2019. Diversity in the Mechanisms of Humin Formation during Composting with Different Materials. Environ. Sci. Technol. 53, 3653-3662. https://doi.org/10.1021/acs.est.8b06401

Guo, J., Cui, X., Sun, H., Zhao, Q., Wen, X., Pang, C., Dong, R., 2018. Effect of glucose and cellulase addition on wet-storage of excessively wilted maize stover and biogas production. Bioresour. Technol. 259, 198-206. https://doi.org/https://doi.org/10.1016/j.biortech.2018.03.041

Hazrati, S., Farahbakhsh, M., Heydarpoor, G., Besalatpour, A.A., 2020. Mitigation in availability and toxicity of multi-metal contaminated soil by combining soil washing and organic amendments stabilization. Ecotoxicol. Environ. Saf. 201, 110807. https://doi.org/10.1016/j.ecoenv.2020.110807

Helmke, P.A., Loeppert, R.H., Soltanpour, P.N., Tabatabai, M.A., Johnson, C.T., Summer, M.E., 1996. Methods of soil analysis, Part 3: Chemical Methods. Soil Science Society of America, Madison, pp. 1018-1020.

He, E., Lü, C., He, J., Zhao, B., Wang, J., Zhang, R., Ding, T., 2016. Binding characteristics of Cu2+ to natural humic acid fractions sequentially extracted from the lake sediments. Environ. Sci. Pollut. Res. 23, 22667-22677. https://doi.org/10.1007/s11356-016-7487-2

He, X.S., Xi, B.D., Cui, D.Y., Liu, Y., Tan, W. Bin, Pan, H.W., Li, D., 2014. Influence of chemical and structural evolution of dissolved organic matter on electron transfer capacity during composting. J. Hazard. Mater. 268, 256-263. https://doi.org/10.1016/j.jhazmat.2014.01.030

He, X.S., Xi, B.D., Gao, R.T., Wang, L., Ma, Y., Cui, D.Y., Tan, W.B., 2015. Using fluorescence spectroscopy coupled with chemometric analysis to investigate the origin, composition, and dynamics of dissolved organic matter in leachate-polluted groundwater. Environ. Sci. Pollut. Res. 22, 8499-8506. https://doi.org/10.1007/s11356-014-4029-7

He, X.S., Xi, B.D., Jiang, Y.H., Li, M.X., Yu, H. Bin, An, D., Yang, Y., Liu, H.L., 2012. Elemental and spectroscopic methods with chemometric analysis for characterizing composition and 
transformation of dissolved organic matter during chicken manure composting. Environ. Technol. (United Kingdom) 33, 2033-2039. https://doi.org/10.1080/09593330.2012.655427 Huang, L., Wang, Q., Zhou, Q., Ma, L., Wu, Y., Liu, Q., Wang, S., Feng, Y., 2020. Cadmium uptake from soil and transport by leafy vegetables: A meta-analysis. Environ. Pollut. 264, 114677. https://doi.org/10.1016/j.envpol.2020.114677

Kizito, S., Luo, H., Wu, S., Ajmal, Z., Lv, T., Dong, R., 2017. Phosphate recovery from liquid fraction of anaerobic digestate using four slow pyrolyzed biochars: Dynamics of adsorption, desorption and regeneration. J. Environ. Manage. 201, 260-267. https://doi.org/https://doi.org/10.1016/j.jenvman.2017.06.057

Lee, M.H., Han, S.J., Lee, Y.K., Ike, I.A., Ok, Y.S., Hur, J., 2020. Enhancing copper binding property of compost-derived humic substances by biochar amendment: Further insight from twodimensional correlation spectroscopy. J. Hazard. Mater. 390, 121128. https://doi.org/10.1016/j.jhazmat.2019.121128

Li, M., Ren, L., Zhang, J., Luo, L., Qin, P., Zhou, Y., Huang, C., Tang, J., Huang, H., Chen, A., 2019. Population characteristics and influential factors of nitrogen cycling functional genes in heavy metal contaminated soil remediated by biochar and compost. Sci. Total Environ. 651, 21662174. https://doi.org/https://doi.org/10.1016/j.scitotenv.2018.10.152

Lingua, G., Todeschini, V., Grimaldi, M., Baldantoni, D., Proto, A., Cicatelli, A., Biondi, S., Torrigiani, P., Castiglione, S., 2014. Polyaspartate, a biodegradable chelant that improves the phytoremediation potential of poplar in a highly metal-contaminated agricultural soil. J. Environ. Manage. 132, 9-15. https://doi.org/10.1016/j.jenvman.2013.10.015

Lipczynska-Kochany, E., 2018. Humic substances, their microbial interactions and effects on biological transformations of organic pollutants in water and soil: A review. Chemosphere 202, 420-437. https://doi.org/10.1016/j.chemosphere.2018.03.104

Liu, L., Li, W., Song, W., Guo, M., 2018. Remediation techniques for heavy metal-contaminated soils: Principles and applicability. Sci. Total Environ. 633, 206-219. https://doi.org/10.1016/j.scitotenv.2018.03.161

Liu, N., Charrua, A.B., Weng, C.-H., Yuan, X., Ding, F., 2015. Characterization of biochars derived from agriculture wastes and their adsorptive removal of atrazine from aqueous solution: $A$ comparative study. Bioresour. Technol. 198, 55-62. https://doi.org/https://doi.org/10.1016/j.biortech.2015.08.129

Luo, H., Lyu, T., Muhmood, A., Xue, Y., Wu, H., Meers, E., Dong, R., Wu, S., 2018. Effect of flocculation pre-treatment on membrane nutrient recovery of digested chicken slurry: 
Mitigating suspended solids and retaining nutrients. Chem. Eng. J. 352, 855-862. https://doi.org/10.1016/j.cej.2018.07.097

Maia, C.M.B.F., Piccolo, A., Mangrich, A.S., 2008. Molecular size distribution of compost-derived humates as a function of concentration and different counterions. Chemosphere 73, 11621166. https://doi.org/https://doi.org/10.1016/j.chemosphere.2008.07.069

Maynaud, G., Druilhe, C., Daumoin, M., Jimenez, J., Patureau, D., Torrijos, M., Pourcher, A.-M., Wéry, N., 2017. Characterisation of the biodegradability of post-treated digestates via the chemical accessibility and complexity of organic matter. Bioresour. Technol. 231, 65-74. https://doi.org/https://doi.org/10.1016/j.biortech.2017.01.057

Muhmood, A., Wu, S., Lu, J., Ajmal, Z., Luo, H., Dong, R., 2018. Nutrient recovery from anaerobically digested chicken slurry via struvite: Performance optimization and interactions with heavy metals and pathogens. Sci. Total Environ. 635, 1-9. https://doi.org/10.1016/j.scitotenv.2018.04.129

Ohno, T., Amirbahman, A., Bro, R., 2008. Parallel factor analysis of excitation-emission matrix fluorescence spectra of water soluble soil organic matter as basis for the determination of conditional metal binding parameters. Environ. Sci. Technol. 42, 186-192. https://doi.org/10.1021/es071855f

Piccolo, A., Spaccini, R., De Martino, A., Scognamiglio, F., di Meo, V., 2019. Soil washing with solutions of humic substances from manure compost removes heavy metal contaminants as a function of humic molecular composition. Chemosphere 225, 150-156. https://doi.org/10.1016/j.chemosphere.2019.03.019

Rodríguez, F.J., Schlenger, P., García-Valverde, M., 2016. Monitoring changes in the structure and properties of humic substances following ozonation using UV-Vis, FTIR and $1 \mathrm{H}$ NMR $\begin{array}{llll}\text { techniques. Sci. } & \text { Total 6nviron. }\end{array}$ https://doi.org/10.1016/j.scitotenv.2015.09.127

Roseline, O., Rexford, M.D., Peter, T., Marina, A.T., Makafui, A.B., Adigun, R.A., Emmanuel, O.T., 2016. Assessment of the levels of cadmium and lead in soil and vegetable samples from selected dumpsites in the Kumasi Metropolis of Ghana. African J. Agric. Res. 11, 1608-1616. https://doi.org/10.5897/ajar2016.10907

Sarwar, N., Imran, M., Shaheen, M.R., Ishaque, W., Kamran, M.A., Matloob, A., Rehim, A., Hussain, S., 2017. Phytoremediation strategies for soils contaminated with heavy metals: Modifications and future perspectives. Chemosphere 171, 710-721. https://doi.org/https://doi.org/10.1016/j.chemosphere.2016.12.116 
Soares da Silva, L., Constantino, I.C., Bento, L.R., Tadini, A.M., Bisinoti, M.C., Boscolo, M., Ferreira, O.P., Mounier, S., Piccolo, A., Spaccini, R., Cornélio, M.L., Moreira, A.B., 2020. Humic extracts from hydrochar and Amazonian Anthrosol: Molecular features and metal binding properties using EEM-PARAFAC and 2D FTIR correlation analyses. Chemosphere 256, 1-12. https://doi.org/10.1016/j.chemosphere.2020.127110

Steinberg, C.E.W., Kamara, S., Prokhotskaya, V.Y., Manusadžianas, L., Karasyova, T.A., Timofeyev, M.A., Jie, Z., Paul, A., Meinelt, T., Farjalla, V.F., Matsuo, A.Y.O., Burnison, B.K., Menzel, R., 2006. Dissolved humic substances - Ecological driving forces from the individual to the ecosystem level? Freshw. Biol. 51, 1189-1210. https://doi.org/10.1111/j.13652427.2006.01571.x

Tang, Y., Li, X., Dong, B., Huang, J., Wei, Y., Dai, X., Dai, L., 2018. Effect of aromatic repolymerization of humic acid-like fraction on digestate phytotoxicity reduction during highsolid anaerobic digestion for stabilization treatment of sewage sludge. Water Res. 143, 436444. https://doi.org/10.1016/j.watres.2018.07.003

Wang, L., Li, X., Tsang, D.C.W., Jin, F., Hou, D., 2020. Green remediation of $\mathrm{Cd}$ and $\mathrm{Hg}$ contaminated soil using humic acid modified montmorillonite: Immobilization performance under accelerated ageing conditions. J. Hazard. Mater. 387, 122005. https://doi.org/10.1016/j.jhazmat.2019.122005

Wang, X., Muhmood, A., Dong, R., Wu, S., 2020. Synthesis of humic-like acid from biomass pretreatment liquor: Quantitative appraisal of electron transferring capacity and metalbinding potential. J. Clean. Prod. 255, 120243. https://doi.org/10.1016/j.jclepro.2020.120243

Wei, L., An, X., Wang, S., Xue, C., Jiang, J., Zhao, Q., Kabutey, F.T., Wang, K., 2017. Effect of hydraulic retention time on deterioration/restarting of sludge anaerobic digestion: Extracellular polymeric substances and microbial response. Bioresour. Technol. 244, 261-269. https://doi.org/https://doi.org/10.1016/j.biortech.2017.07.110

Wei, L., Li, J., Xue, M., Wang, S., Li, Q., Qin, K., Jiang, J., Ding, J., Zhao, Q., 2019. Adsorption behaviors of $\mathrm{Cu} 2+, \mathrm{Zn} 2+$ and $\mathrm{Cd} 2+$ onto proteins, humic acid, and polysaccharides extracted from sludge EPS: Sorption properties and mechanisms. Bioresour. Technol. 291, 121868. https://doi.org/10.1016/j.biortech.2019.121868

Wu, G., Kang, H., Zhang, X., Shao, H., Chu, L., Ruan, C., 2010. A critical review on the bio-removal of hazardous heavy metals from contaminated soils: Issues, progress, eco-environmental concerns and opportunities. J. Hazard. Mater. 174, 1-8. 
https://doi.org/https://doi.org/10.1016/j.jhazmat.2009.09.113

Wu, H., Qi, Y., Dong, L., Zhao, X., Liu, H., 2019. Revealing the impact of pyrolysis temperature on dissolved organic matter released from the biochar prepared from Typha orientalis. Chemosphere 228, 264-270. https://doi.org/10.1016/j.chemosphere.2019.04.143

Xiao, X., Xi, B.D., He, X.S., Zhang, H., Li, D., Zhao, X.Y., Zhang, X.H., 2019. Hydrophobicitydependent electron transfer capacities of dissolved organic matter derived from chicken $\begin{array}{llll}\text { manure } & \text { compost. } & \text { 222, }\end{array}$ https://doi.org/10.1016/j.chemosphere.2019.01.173

Xu, H., Ji, L., Kong, M., Jiang, H., Chen, J., 2019. Molecular weight-dependent adsorption fractionation of natural organic matter on ferrihydrite colloids in aquatic environment. Chem. Eng. J. 363, 356-364. https://doi.org/10.1016/j.cej.2019.01.154

Yu, Z., Liu, X., Zhao, M., Zhao, W., Liu, J., Tang, J., Liao, H., 2019. Bioresource Technology Hyperthermophilic composting accelerates the humification process of sewage sludge: Molecular characterization of dissolved organic matter using EEM - PARAFAC and twodimensional correlation spectroscopy. Bioresour. Technol. 274, 198-206. https://doi.org/10.1016/j.biortech.2018.11.084

Zhang, S., Wen, J., Hu, Y., Fang, Y., Zhang, H., Xing, L., Wang, Y., Zeng, G., 2019. Humic substances from green waste compost: An effective washing agent for heavy metal ( $\mathrm{Cd}, \mathrm{Ni})$ removal from contaminated sediments. J. Hazard. Mater. 366, 210-218. https://doi.org/10.1016/j.jhazmat.2018.11.103

Zhang, W., Wei, Q., Wu, S., Qi, D., Li, W., Zuo, Z., Dong, R., 2014. Batch anaerobic co-digestion of pig manure with dewatered sewage sludge under mesophilic conditions. Appl. Energy 128, 175-183. https://doi.org/https://doi.org/10.1016/j.apenergy.2014.04.071

Zhao, X., Tan, W., Peng, J., Dang, Q., Zhang, H., Xi, B., 2020. Biowaste-source-dependent synthetic pathways of redox functional groups within humic acids favoring pentachlorophenol dechlorination in composting process. Environ. Int. 135, 105380. https://doi.org/10.1016/j.envint.2019.105380 


\section{Figure captions}

Fig. 1. The cumulative and daily methane produced during chicken manure and corn stover anaerobic digestion.

Fig. 2. Excitation-emission matrix fluorescence spectra of organic matter during anaerobic digestion of chicken manure (a) and corn stover (c), and the relative proportion of EEM-PARAFAC components during anaerobic digestion process with chicken manure (b) and corn stover (d). (C1, C3: Humic-like substances; C2: Fulvic-like substance; C4: Tyrosine-like substance; C5: Tryptophan-like substance)

Fig. 3. Results of normalized FTIR absorbance of humic acid from chicken manure (a) and corn stover (b) anaerobic digestion, and the relative proportion of main functional groups in HA from chicken manure (c, e, g) and corn stover (d, f, h).

Fig. 4. Variations in fluorescent intensities of humic acid derived from chicken manure (a-c) and corn stover ( $d-f)$ anaerobic digestion with increasing initial concentrations of copper ( $a$ and $d)$, nickel ( $b$ and e), and cobalt ( $c$ and f). The lines in the figures are the Stern-Volmer model simulations. The numbers near the line represent decreased fluorescent intensity values.

Fig. 5. Principal component analysis biplot of the HA structural changes during the anaerobic digestion process with chicken manure (a) and corn stover (b).

Fig. 6. Correlation between HA functional groups and metal-binding derived from the fast (a-d) and slow (e-h) methane production stages of chicken manure and corn stover anaerobic digestion. 


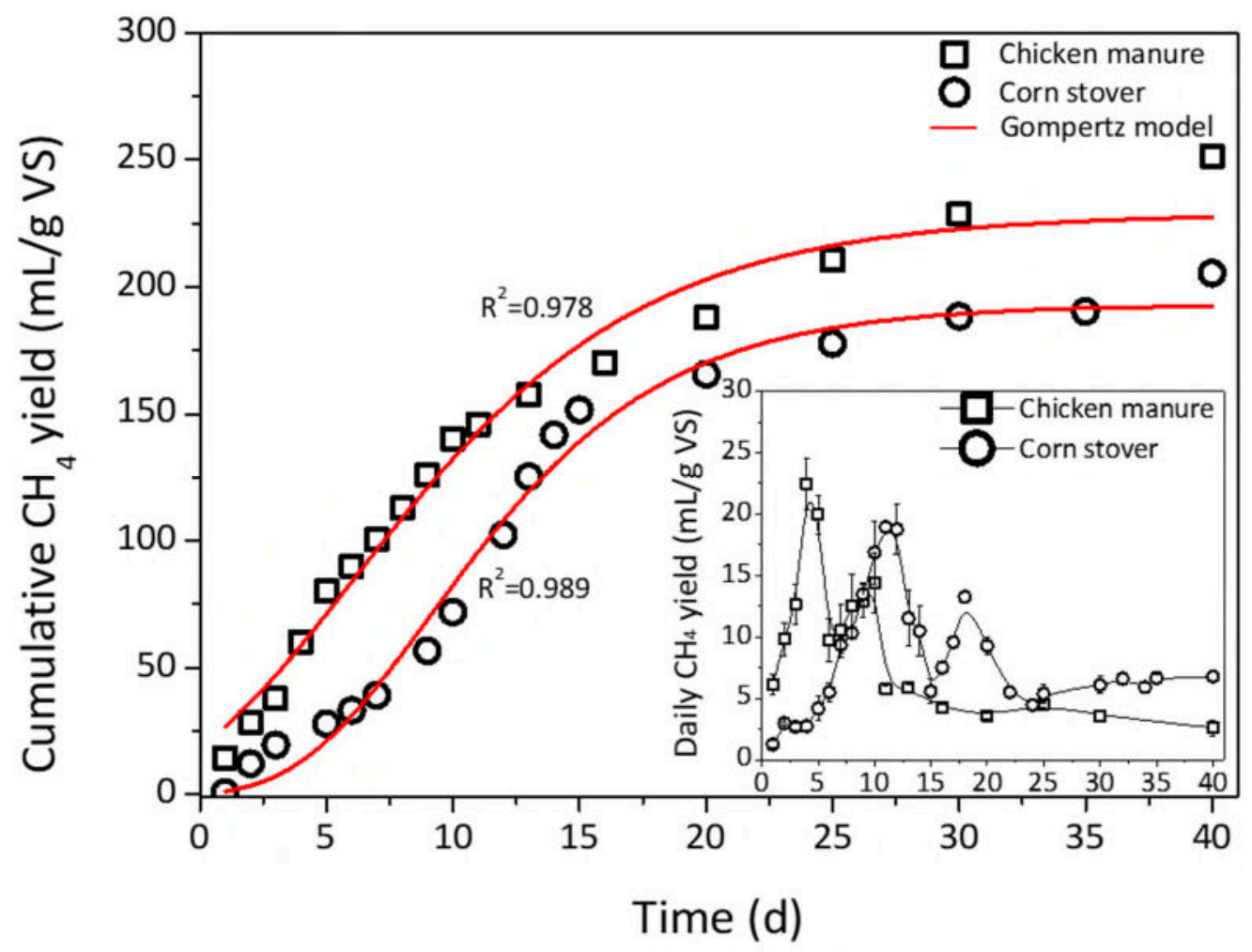

Fig. 1. The cumulative and daily methane produced during chicken manure and corn stover anaerobic digestion. 

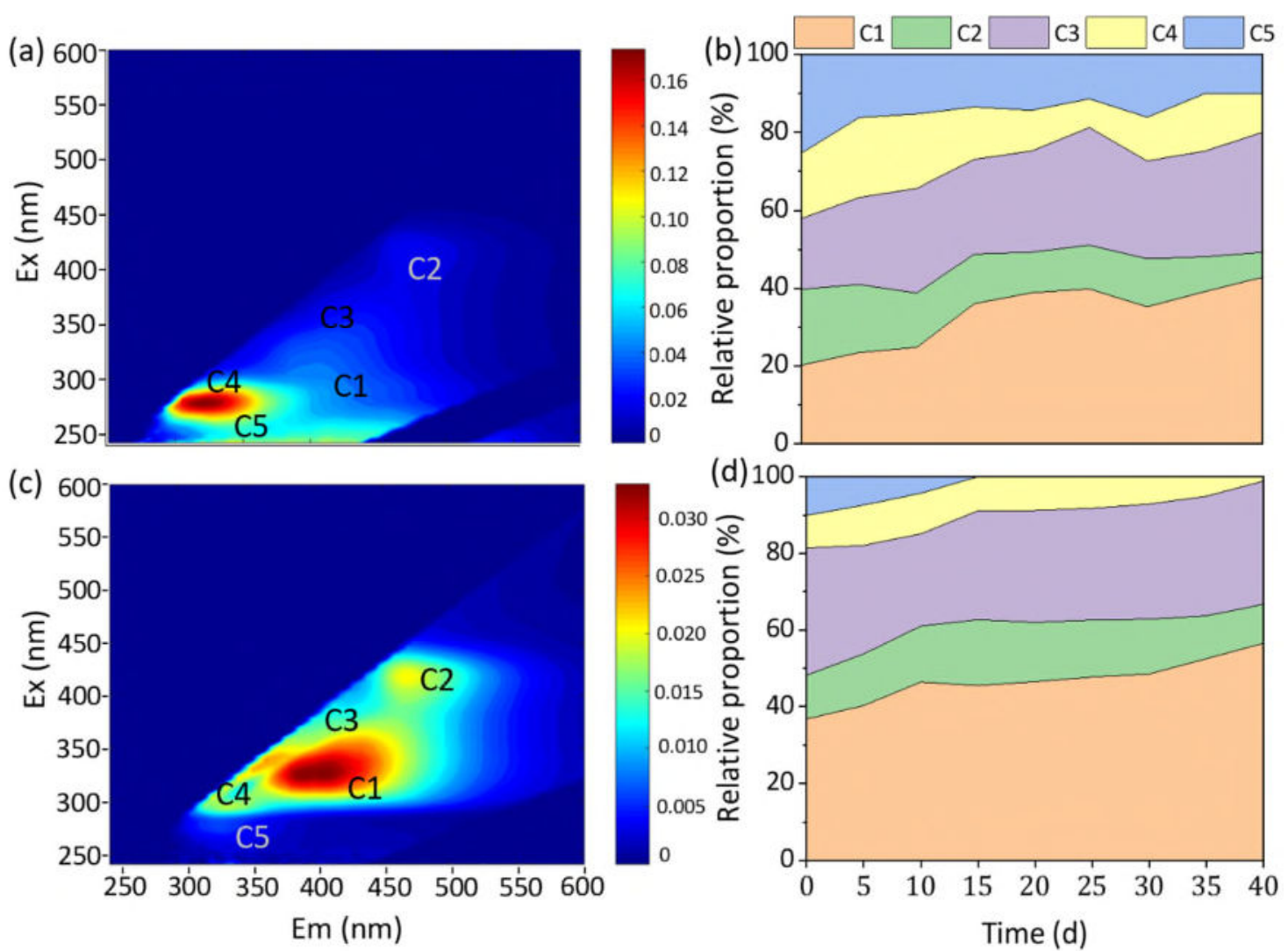

Fig. 2. Excitation-emission matrix fluorescence spectra of organic matter during anaerobic digestion of chicken manure (a) and corn stover (c), and the relative proportion of EEM-PARAFAC components during anaerobic digestion process with chicken manure (b) and corn stover (d). (C1, C3: Humic-like substances; C2: Fulvic-like substance; C4: Tyrosine-like substance; C5: Tryptophan-like substance) 


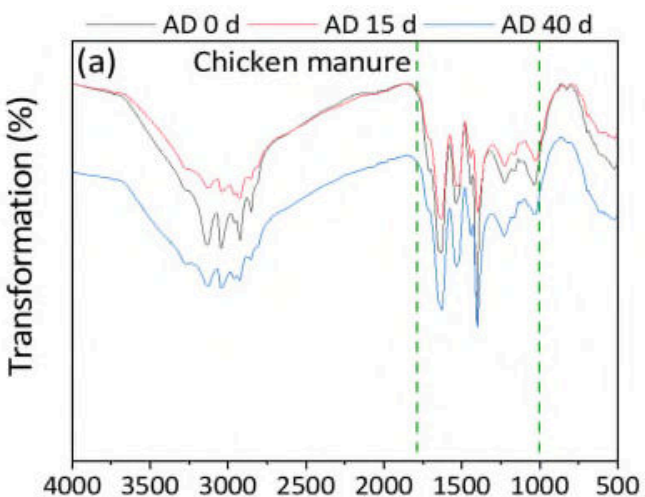

Wavenumber $\left(\mathrm{cm}^{-1}\right)$
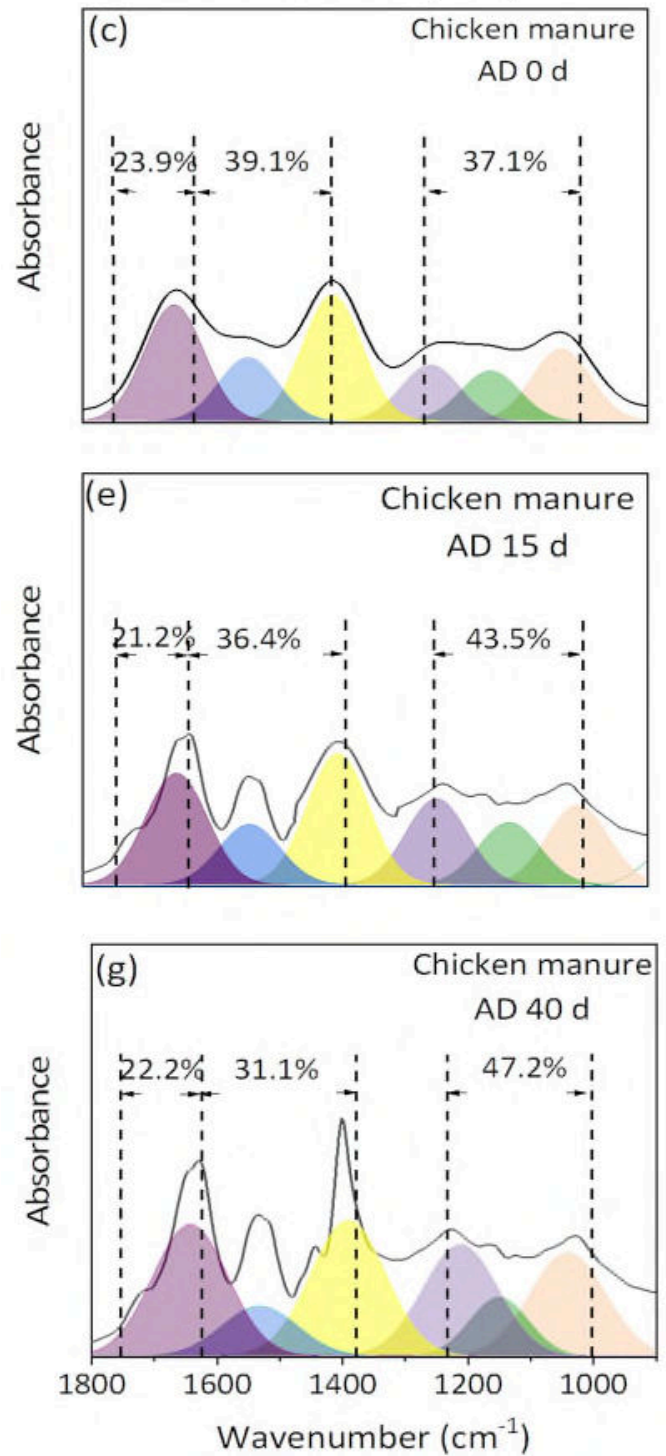
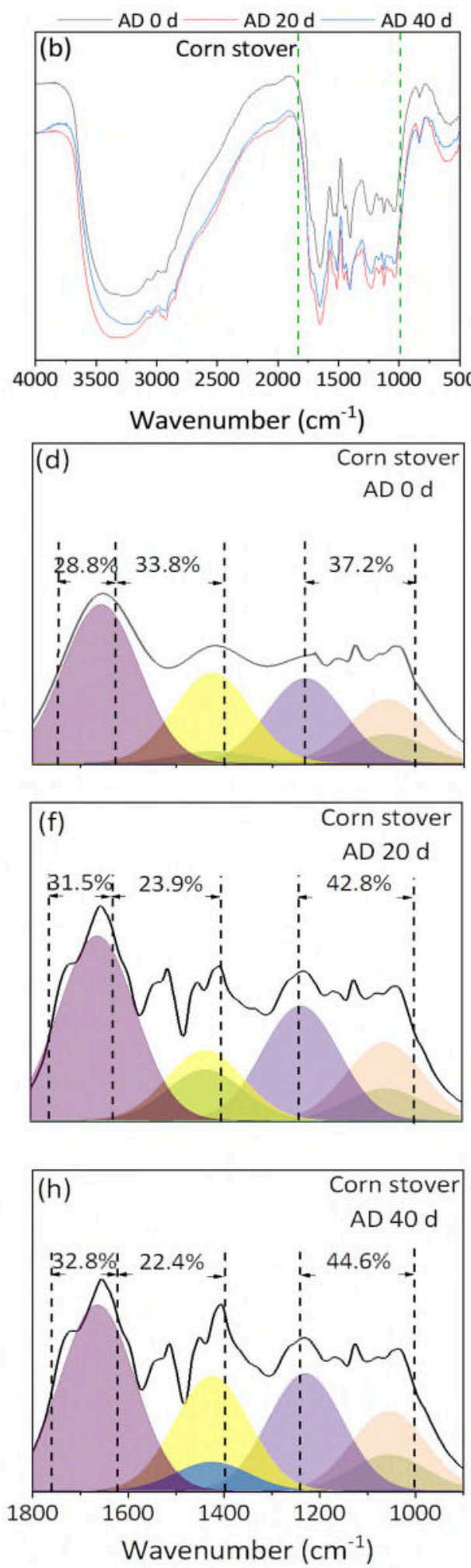

Fig. 3. Results of normalized FTIR absorbance of humic acid from chicken manure (a) and corn stover (b) anaerobic digestion, and the relative proportion of main functional groups in HA from chicken manure (c, e, g) and corn stover $(d, f, h)$. 

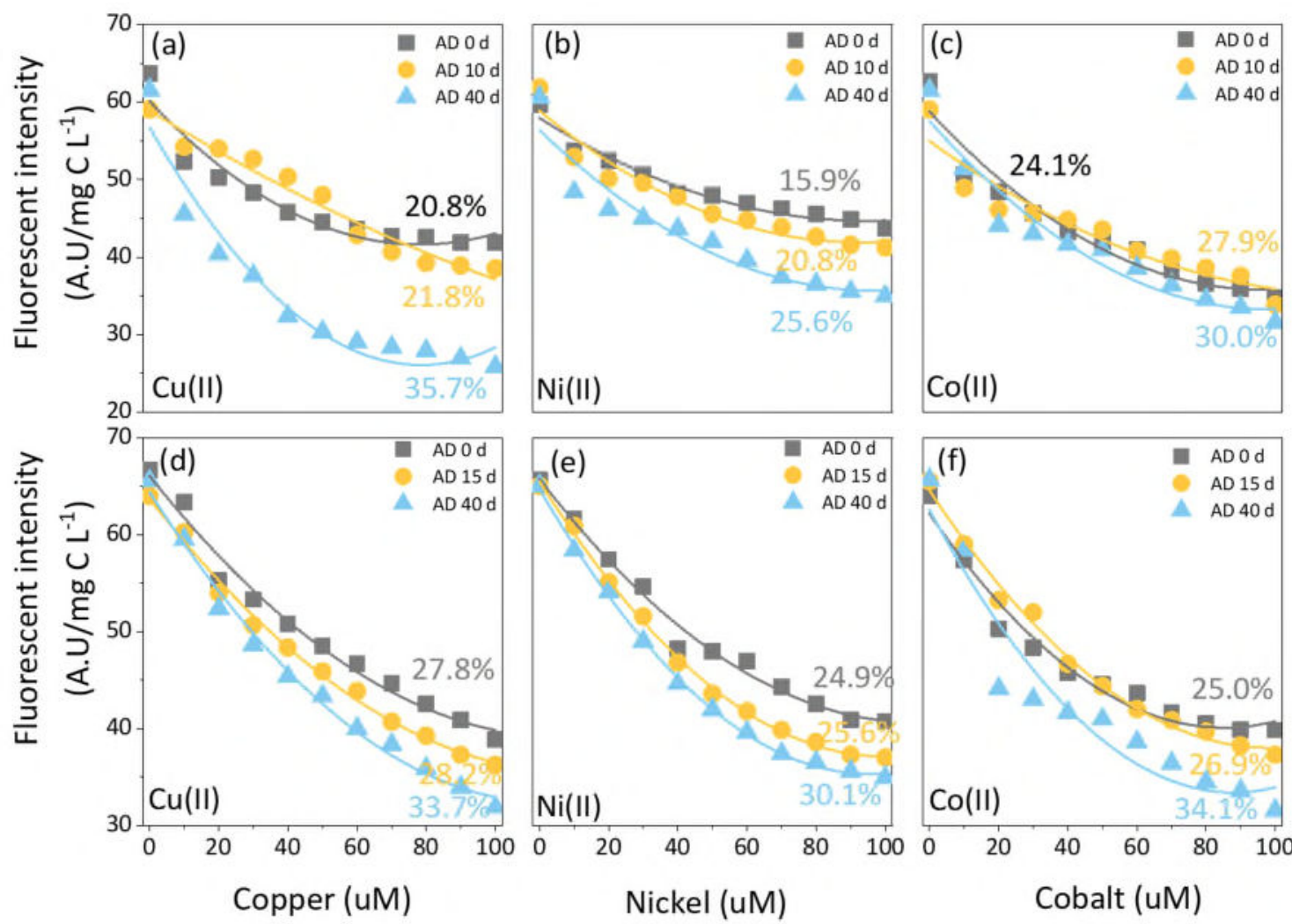

Fig. 4. Variations in fluorescent intensities of humic acid derived from chicken manure $(a-c)$ and corn stover (d-f) anaerobic digestion with increasing initial concentrations of copper ( $a$ and $d)$, nickel ( $b$ and e), and cobalt (c and f). The lines in the figures are the Stern-Volmer model simulations. The numbers near the line represent decreased fluorescent intensity values. 

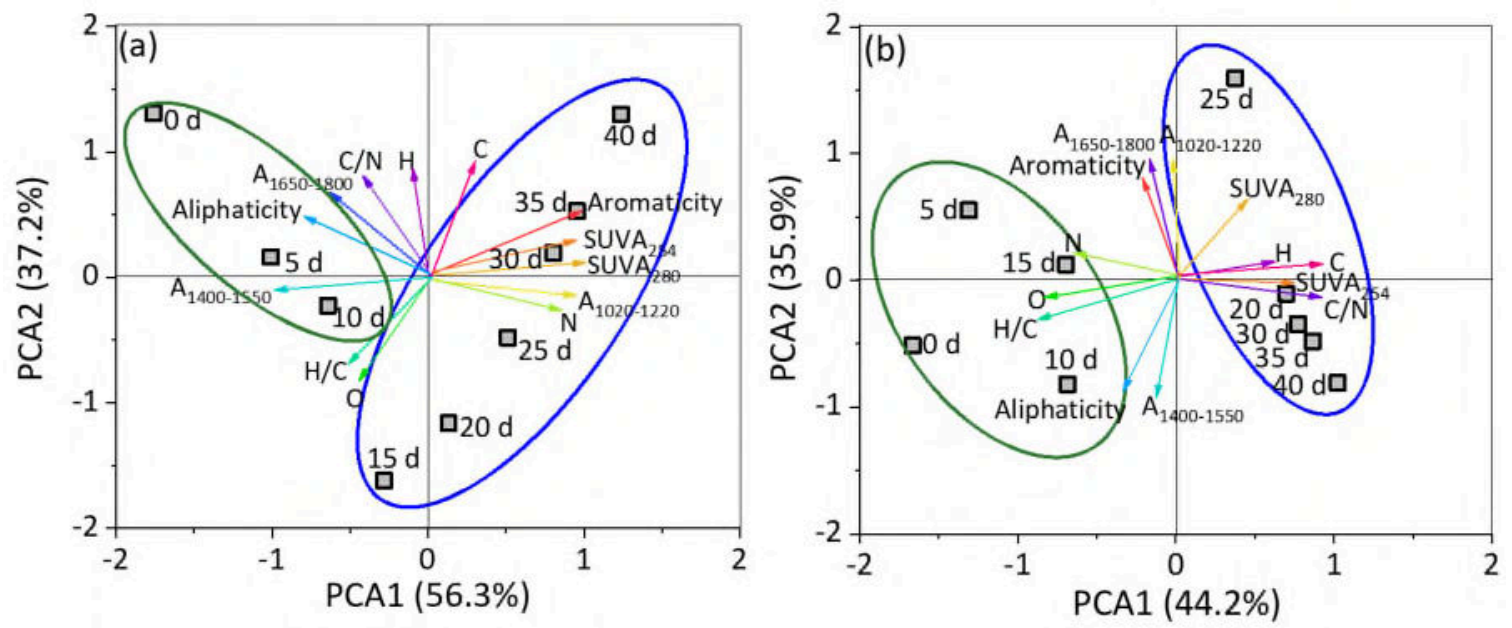

Fig. 5. Principal component analysis biplot of the HA structural changes during the anaerobic digestion process with chicken manure (a) and corn stover (b). 

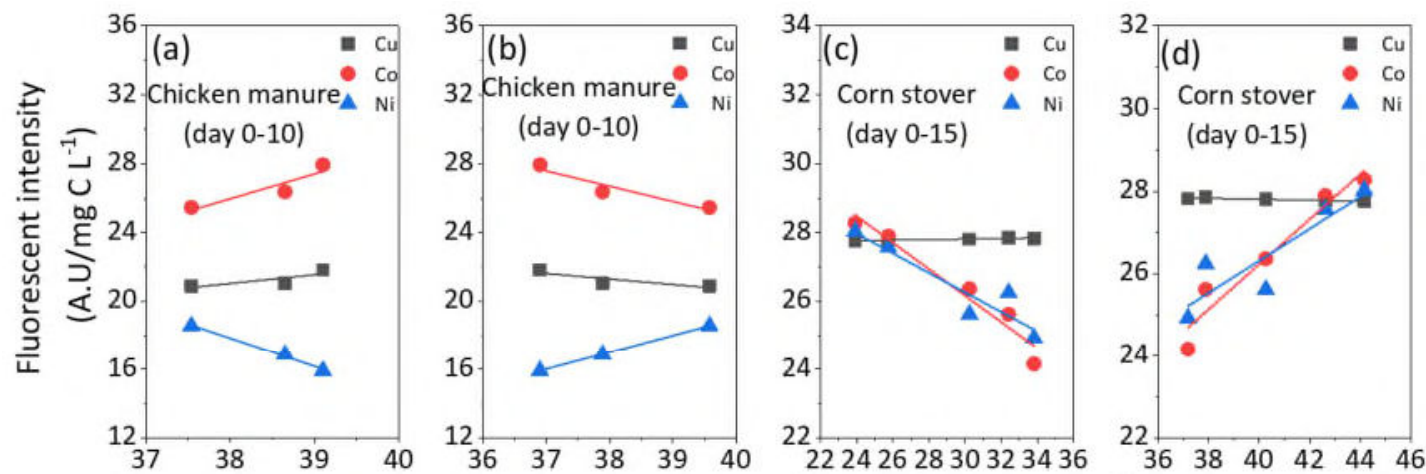

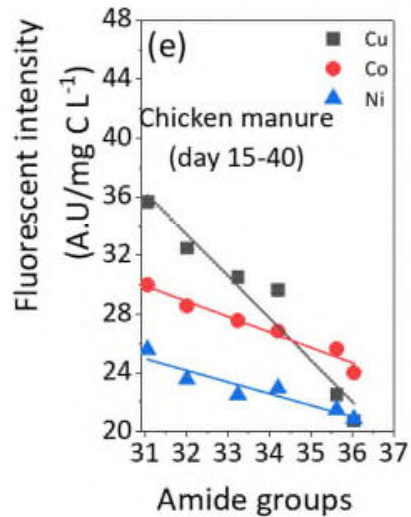

(\%)

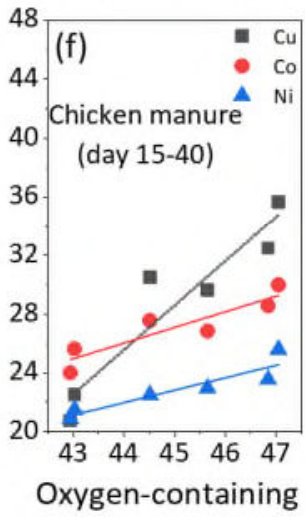

groups (\%)

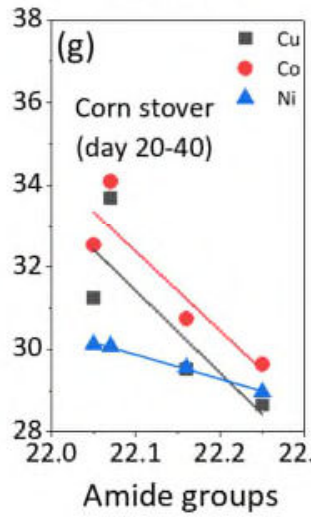

(\%)

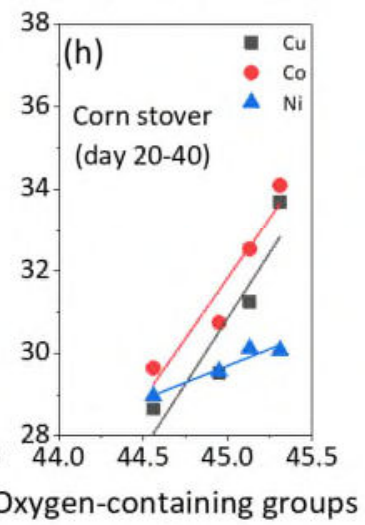

(\%)

Fig. 6. Correlation between HA functional groups and metal-binding derived from the fast (a-d) and slow (e-h) methane production stages of chicken manure and corn stover anaerobic digestion. 


\section{Table 1}

The SUVA values (SUVA 254 and SUVA 280 ) and the elemental composition ratio of humic acid from anaerobic digestion of chicken manure and corn stover.

\begin{tabular}{lllllllll}
\hline \multirow{2}{*}{$\begin{array}{l}\text { Time } \\
\text { (d) }\end{array}$} & \multicolumn{7}{l}{ Chicken manure } & \multicolumn{7}{l}{ Corn stover } \\
\cline { 2 - 9 } & SUVA $_{254}$ & SUVA $_{280}$ & C/N & H/C & SUVA $_{254}$ & SUVA $_{280}$ & C/N & H/C \\
\hline 0 & $0.85 \pm 0.01$ & $0.98 \pm 0.08$ & $6.34 \pm 0.08$ & $2.18 \pm 0.03$ & $1.05 \pm 0.01$ & $1.32 \pm 0.02$ & $5.75 \pm 0.10$ & $1.77 \pm 0.02$ \\
5 & $1.25 \pm 0.05$ & $1.04 \pm 0.05$ & $4.94 \pm 0.10$ & $2.03 \pm 0.01$ & $2.56 \pm 0.02$ & $1.78 \pm 0.02$ & $9.59 \pm 0.22$ & $1.53 \pm 0.01$ \\
10 & $1.12 \pm 0.03$ & $1.10 \pm 0.07$ & $4.54 \pm 0.09$ & $2.01 \pm 0.02$ & $2.45 \pm 0.03$ & $2.39 \pm 0.01$ & $8.48 \pm 0.14$ & $1.56 \pm 0.01$ \\
15 & $1.14 \pm 0.03$ & $1.20 \pm 0.03$ & $4.06 \pm 0.11$ & $2.02 \pm 0.02$ & $2.50 \pm 0.02$ & $2.88 \pm 0.03$ & $8.83 \pm 0.15$ & $1.42 \pm 0.01$ \\
20 & $1.20 \pm 0.09$ & $1.37 \pm 0.08$ & $3.99 \pm 0.12$ & $1.99 \pm 0.01$ & $2.23 \pm 0.03$ & $3.21 \pm 0.02$ & $7.41 \pm 0.14$ & $1.57 \pm 0.01$ \\
25 & $1.40 \pm 0.11$ & $1.41 \pm 0.10$ & $4.01 \pm 0.07$ & $1.89 \pm 0.02$ & $1.92 \pm 0.04$ & $2.58 \pm 0.04$ & $9.35 \pm 0.24$ & $1.47 \pm 0.02$ \\
30 & $1.52 \pm 0.07$ & $1.55 \pm 0.11$ & $4.53 \pm 0.09$ & $1.79 \pm 0.02$ & $1.85 \pm 0.05$ & $2.34 \pm 0.04$ & $7.11 \pm 0.13$ & $1.63 \pm 0.03$ \\
35 & $1.63 \pm 0.11$ & $1.59 \pm 0.06$ & $4.72 \pm 0.11$ & $1.81 \pm 0.01$ & $1.89 \pm 0.02$ & $2.41 \pm 0.03$ & $7.25 \pm 0.16$ & $1.64 \pm 0.02$ \\
40 & $1.81 \pm 0.17$ & $1.84 \pm 0.09$ & $5.01 \pm 0.07$ & $1.78 \pm 0.02$ & $1.93 \pm 0.01$ & $2.22 \pm 0.04$ & $6.73 \pm 0.09$ & $1.66 \pm 0.01$ \\
\hline
\end{tabular}

